\title{
La propiedad en el constitucionalismo liberal cubano de los siglos XIX $\mathrm{y} \mathrm{xx}^{*}$
} Property in Cuban Liberal Constitutionalism
of The Nineteenth and Twentieth Centuries

\section{Santiago Antonio Bahamonde Rodríguez ${ }^{* *}$}

\section{RESUMEN}

El presente artículo tratará sobre la propiedad en el constitucionalismo liberal cubano de los siglos XIX y Xx. Comenzaremos por abordar las peculiaridades del liberalismo cubano en el contexto del siglo xIX, matizado por la pervivencia de la esclavitud y de la relación colonial con España que incidieron en su eclosión y desarrollo. En segundo lugar, se trabajará la propiedad en el constitucionalismo español, dada su influencia en la doctrina y la práctica liberal cubana. En tercer lugar, se tratará la propiedad en los antecedentes constitucionales cubanos del siglo XIX, con énfasis en su impronta liberal. Por último, se analizará la Constitución cubana de 1901 como sintesis del pensamiento liberal cubano del siglo XIX en torno a la propiedad. Con ello se podrá concluir que la Constitución de 1901 representó la cúspide y cierre del pensamiento liberal cubano del siglo xIX.

PALABRAS CLAVE: Propiedad, liberalismo, constitucionalismo, Cuba.

\begin{abstract}
The current article will deal with property in Cuban Liberal Constitutionalism of the Nineteenth and Twentieth Centuries. We begin by addressing the peculiarities of Cuban liberalism in the context of the Nineteenth Century, shaded by the continued existence of slavery and the colonial relationship with Spain that influenced its emergence and development. In second place, property will be discuss within Spanish Constitutionalism, given its influence on Cuban liberal doctrine and practice. Thirdly, property will be treated within the Cuban Constitutional past of the Nineteen Century, with emphasis on its liberal imprint. Finally, the Cuban Constitution of 1901 will be analyzed as a synthesis of Nineteenth-Century Cuban liberal thought on property. With this it will be possible to conclude that the Constitution of 1901 represented the height and fall of the Cuban liberal thought of Nineteen Century.
\end{abstract}

KEY WORDS: Property, Liberalism, Constitutionalism, Cuba

\footnotetext{
* Artículo de revisión. Recibido el 11 de noviembre de 2017 y aceptado para su publicación el 26 de junio de 2018.

** Profesor en la Facultad de Derecho de la Universidad de La Habana, Cuba. (santiago@lex.uh.cu) orcid.org/00000003-0383-6543
} 


\section{SUMARIO}

1. Ideas iniciales

2. El liberalismo cubano, una visión histórica

3. El impacto de la propiedad en el constitucionalismo español del siglo xIX en Cuba

4. La visión liberal de la propiedad en los antecedentes del constitucionalismo cubano del siglo XIX

5. La constitución cubana de 1901, síntesis del pensamiento liberal cubano del siglo XIX

6. Conclusiones

\section{Ideas iniciales}

Desde los albores del derecho, la propiedad ha aparecido como una de las principales y más controvertidas categorías económicas y jurídicas. Como expresión jurídica de una realidad socioeconómica, la propiedad ha sufrido un complejo proceso de evolución para adecuarse a las siempre cambiantes condiciones de la sociedad. Desde el siglo XVIII ha sido incluida como una de las piezas fundamentales de los textos constitucionales elaborados a partir de entonces. En ese sentido, es importante preguntarse: ¿por qué la presencia de la propiedad en los textos constitucionales?

Para responder a esta pregunta, debemos entender que la ascendente burguesía valoraba a la propiedad -entiéndase privada- como algo connatural al hombre, necesario para su plena realización como individuo y como ciudadano. ${ }^{1}$ De ahí que se le considerara como un derecho oponible al Estado salvo en las circunstancias identificadas por ley. ${ }^{2}$ De esta manera, apareció recogida en la Declaración de los Derechos del Hombre y del Ciudadano de 1789. Por lo tanto, se desarrolló en el constitucionalismo moderno una doctrina liberal que estuvo presente hasta los comienzos del siglo xx y que resultó de notable influencia en Cuba.

De esta forma, resulta innegable que nos encontramos ante un tema de gran 180 riqueza histórica, teórica y legislativa, que es imprescindible abordar para el mejor conocimiento de la historia constitucional, especialmente la propiedad, institución común a todos los ordenamientos jurídicos. En el caso cubano,

\footnotetext{
'En el siglo xvIII, apareció una nueva tesis como resultado del derecho natural de todo hombre a la vida. Los defensores iniciales de este criterio, Locke y Hobbes, remarcaban que el derecho a poseer bienes se derivaba de la existencia humana por el hecho de su nacimiento. Esta escuela tuvo gran predicamento en los siglos XVIII y XIX. Entre sus exponentes se encontraron, además de los ya mencionados, figuras como Montesquieu, Malby, Hamilton, Adam Smith, Benjamin Constant y Portalis, entre otros.

${ }^{2}$ Como el caso de la expropiación forzosa, la confiscación y los impuestos.
} 
cobra aún mayor vigencia y actualidad por la ausencia de estudios científicos completos sobre dicha materia. Esto se debe a que nuestra historiografía ha tratado este tema desde dos puntos de vista: por un lado, los historiadores han hecho hincapié en los elementos vinculados con la economía y la sociedad, no propiamente implicados en el tema jurídico; por otra, los estudiosos del derecho han realizado una descripción del tema, sin profundizar en él.

Sin duda, esta ausencia en la historiografía jurídica ha generado problemas científicos a la hora de abordar el tema en cuestión. Los investigadores, pese a la copiosa bibliografía, sólo pueden obtener una visión parcial de un fenómeno tan complejo, que trasciende al campo de la ciencia jurídica. Dicha situación se agrava debido a la escasez de estudios sobre las transformaciones de esta institución durante el siglo xIX cubano y su impacto en la sociedad. ¿Cómo se incorporó la doctrina liberal acerca de la propiedad al constitucionalismo cubano del siglo xIx y albores del xx? No hay duda de que el análisis de este período cardinal en la historia de Cuba resulta trascendental para explicar el pensamiento político y jurídico en relación con la propiedad, aparejado a la formación de la nación cubana.

Es por ello que se ha decidido dedicar nuestro estudio a esta institución en el constitucionalismo liberal cubano entre el siglo XIX y de los albores del XX. Por ende, se propone develar, desde la perspectiva constitucional, el proceso de evolución histórica de la propiedad en Cuba durante el período de 1800 a 1901 . Partiendo de lo anterior, se considera como presupuesto de esta investigación que la concepción liberal cubana acerca de la propiedad asumió los postulados esenciales del liberalismo europeo, pese a las diferencias doctrinales en temas vinculados con esta institución jurídica. No obstante, el contexto en que se desenvolvió a lo largo de la centuria impidió llevarla a vías de hecho, hasta la elaboración de la Constitución de 1901 que inició la era republicana en Cuba.

En consecuencia, se propone como objetivo del presente estudio demostrar que el proceso de evolución histórica constitucional de la propiedad en el siglo XIX cubano se atuvo teóricamente a la doctrina liberal sobre la propiedad, más allá de los diferentes matices y tendencias. Sin embargo, no pudo lograr su pleno acabado hasta la elaboración de la Constitución de 1901.

En función del cumplimiento del objetivo, se ha dividido la obra en cuatro partes fundamentales. En la primera, se abordará el pensamiento liberal cubano del siglo xIX, señalando sus continuidades y rupturas con el europeo. El segundo apartado se dedicará al análisis de la propiedad en el constitucionalismo español del siglo XIx, valorando el modo en que se reguló esa institución en las leyes fundamentales de España y el impacto que tuvieron en Cuba. En el tercero, abordaremos cómo se expresó la propiedad en el 
constitucionalismo cubano del siglo xix, valorando la manera en la que fue regulada esta institución jurídica en los proyectos y textos constitucionales patrios y sus avatares a lo largo de la centuria. A continuación, cerraremos con la valoración de la propiedad en la Constitución de 1901 como síntesis del pensamiento liberal decimonónico.

A la hora de tratar la relación entre propiedad y Constitución no pueden desarrollarse todas las transformaciones sobre bienes a lo largo del siglo XIX, pues ello transversaliza a todo el derecho. De ahí que sólo se abordarán aquellos puntos de contacto con las constituciones que resultan destacables en el presente estudio. En primer lugar, el hecho de que la propiedad aparezca reconocida en las Cartas Magnas como un derecho fundamental; asimismo, por su vinculación con temáticas como la salvaguarda del patrimonio de los particulares contra la acción arbitraria del Estado, la facultad de imponer tributos y el otorgamiento de derechos políticos (aspectos recurrentes en el constitucionalismo del XIX).

Con esto en cuenta, se espera obtener una sistematización histórica de la propiedad en el constitucionalismo cubano del siglo XIX, señalando su fundamento liberal y su instauración en la normativa constitucional cubana del período de 1800 a 1901 .

\section{El liberalismo cubano, una visión histórica}

Un estudio del liberalismo cubano debe partir del análisis de los antecedentes que en materia de propiedad y de derechos individuales significaron los Estados Unidos y Francia para la isla, los cuales influyeron en el desarrollo político cubano. En primer lugar, hay que tener presente que el liberalismo cubano, en especial su concepción sobre la propiedad, fue un digno hijo de su tiempo. Por ello, como premisa, se debe analizar el contexto internacional, en especial las doctrinas políticas y jurídicas y las declaraciones de derechos que le sirvieron de antecedente inmediato.

$\mathrm{Al}$ respecto, la doctrina desde finales del XVII insistió en el reconocimiento de la propiedad como un derecho esencial, básico para el ser humano. ${ }^{3} \mathrm{Al}$ respecto un autor comentó: "Each man had natural right to his life, liberty and property". ${ }^{4}$ En este sentido se expresó Thomas Jefferson al decir: "The object of government is, therefore, the protection of pre-existing God given rights, which all men enjoy under the law of nature". ${ }^{5}$ A ello se unieron las primeras

\footnotetext{
${ }^{3}$ Véase a Hobbes, Locke, Rousseau, Montesquieu, entre otros.

${ }^{4}$ Hockem, Homer, The Constitutional history of the United States, Nueva York, The Mac Millan Company, 1959, p. 16.

5 Jefferson, Thomas, The Political writings of Thomas Jefferson, Nueva York, The Liberal Arts Press, 1959, p. xix.
} 
declaraciones de derechos a partir del Bill of Rigths, las cuales incluyeron a la propiedad como un elemento esencial en su articulado. De tal manera, se debe señalar que la Declaración de Independencia norteamericana dedicó todo un acápite a las quejas contra las violaciones reales contra el derecho de propiedad. ${ }^{6}$ En el propio documento, se proclama el derecho de todo individuo a "la vida, la libertad y la búsqueda de la felicidad". ${ }^{7}$ Como texto de consenso entre las diferentes fuerzas revolucionarias, la Declaración servía de programa político y de declaración de derechos de aquella, cuya influencia es detectable en los padres del texto francés de $1789 .^{8}$

Sin embargo, resulta extraño que en la Constitución de 1787 -obra más madura- no se positivizaran los derechos a nombre de los cuales se había hecho la Revolución. Esta decisión levantó la protesta de los sectores democráticos contra la Convención. Los defensores de su incorporación los consideraban indispensables para la obra constitucional y temían que sin esta garantía el Gobierno pudiese atacarlos, al igual que ya había hecho el británico.

En consecuencia, fue introducida en la Constitución con las primeras diez enmiendas. En la quinta se dispuso que "no se podrá quitar la vida, la libertad o los bienes, sin el debido procedimiento legal, ni se podrá tomar la propiedad particular para objeto de utilidad pública, sin justa compensación". ${ }^{9} \mathrm{~A}$ esta se le incorporó la decimocuarta, que extendió -en su sección primeraesta prohibición a los gobiernos estaduales. ${ }^{10}$ Con el propósito de evitar el acceso al poder de personas dispuestas a atentar contra el régimen de propiedad existente $-\mathrm{y}$ de esa forma protegerlo-, los convencionales siguieron la práctica inglesa y la de las asambleas coloniales, anteriores a la independencia: para ser elector se exigía la propiedad de determinada cantidad de bienes, que variaba según el Estado. ${ }^{11}$

\footnotetext{
${ }^{6}$ Véanse en la Declaración, los párrafos contra los altos impuestos, los monopolios comerciales y el alojamiento de tropas. Rodriguez Abrahantes, Dagoberto, Historia de los Estados Unidos. Selección de Lecturas, tomo 1, La Habana, Félix Varela, 2003, pp. 305-309.

7 En el texto original aparecia la palabra propiedad, que Jefferson sustituyó por búsqueda de la felicidad. En opinión de Eliot y Morris estos autores, para ser feliz había que poseer bienes materiales que garantizaran la vida, y permitieran la tranquilidad espiritual. Elot Morrison, Samuel y Steele Commanger, Henry, Historia de los Estados Unidos de Norteamérica, tomo 1, México, Fondo de Cultura Económica, 1951, p. 196.

${ }^{8}$ Los franceses quisieron consagrar esos derechos en un texto similar, aunque más detallado, pero el preámbulo del mismo usa una fórmula similar a la norteamericana.

${ }^{9}$ Véase la Quinta Enmienda, en Rodriguez Abrahantes, Dagoberto, Historia de los Estados Unidos. Selección de Lecturas, tomo 1, La Habana, Félix Varela, 2003, p. 338.

${ }^{10}$ Rodriguez Abrahantes, Dagoberto, Historia de los Estados Unidos. Selección de Lecturas, tomo 1, La Habana, Félix Varela, 2003.

"Faulkner, Harold Underwood, Historia económica de los Estados Unidos, tomo 1, La Habana, Ainsenson, Editorial de Ciencias Sociales, 1972.
} 
El caso francés resultó más complicado. Influyó notablemente en el pensamiento de la burguesía española, así como en su acción política durante las primeras décadas del siglo XIX. Como en su momento advirtió Engels, "En Francia, la Revolución rompió plenamente con las tradiciones del pasado, barrió los últimos vestigios del feudalismo y creó, con el Código Civil, una adaptación magistral a las valoraciones capitalistas modernas del antiguo Derecho romano".

Esto explica que uno de los primeros documentos jurídicos relevantes de la naciente Revolución fuera la Declaración de Derechos del Hombre y del Ciudadano de 1789. El artículo 17 declaraba: "Siendo la propiedad un derecho inviolable y sagrado, nadie puede ser privado de ella, si no es en los casos en que la necesidad pública, legalmente comprobada, lo exija evidentemente, y bajo la condición de una indemnización justa". ${ }^{12}$ Como se colige, pese a los atributos altisonantes con los que se definió esa institución jurídica, se incluyó una necesaria limitación de orden público que fue recogida por el constitucionalismo posterior y que todavía pervive en la actualidad.

La Constitución de 1791 consagró a la propiedad de una forma distinta al artículo 17 de la Declaración de 1789: "La Constitución garantiza la inviolabilidad de las propiedades, o la justa y previa indemnización de las que, por necesidad pública, legalmente verificada, se exija su sacrificio. Los bienes destinados a los actos de culto y a cualquier servicio de utilidad pública pertenecen a la nación y están en todo momento a su disposición”. ${ }^{13}$

Según se aprecia, la propiedad ya no era sagrada e inviolable; por otro lado, se reafirmó el proceso confiscatorio de los bienes del patrimonio real y del clero. Incluso se incluyó un acápite mediante el cual se aseguraban, por la Constitución, todas las ventas realizadas de acuerdo con la ley. Este debe entenderse como una garantía para quienes habían adquirido bienes nacionales.

La Constitución de 1793 tiene un articulado más complejo. En el primero se establece que "El fin de la sociedad es la felicidad común. El gobierno se instituye para garantizar al hombre el goce de sus derechos naturales e imprescriptibles". ${ }^{14}$ El segundo aclara la idea anterior al plantear: "Estos derechos son libertad, igualdad, seguridad y propiedad". ${ }^{15}$ Asimismo, el artículo 16 amplía este concepto al definir su contenido, algo que en buena técnica no corresponde a una

\footnotetext{
${ }^{12}$ Faulkner, Harold Underwood, Historia económica de los Estados Unidos, tomo 1, La Habana, Ainsenson, Editorial de Ciencias Sociales, 1972, p. 22.

${ }^{13}$ Torremocha, Manuel, "Constitución francesa 1791", ies Las Musas. [Consulta: 33 de enero, 2010]. Disponible en: www. ieslasmusas.org/geohistoria/constiticionfrancesa1791.pdf

${ }^{14}$ Torremocha, Manuel, "Constitución francesa 1791", ies Las Musas. [Consulta: 33 de enero, 2010]. Disponible en: www. ieslasmusas.org/geohistoria/constiticionfrancesa1791.pdf

${ }^{15}$ Torremocha, Manuel, "Constitución francesa de 1793", IES Las Musas. [Consulta: 33 de enero, 2010]. Disponible en: www.ieslasmusas.org/geohistoria/constiticionfrancesa 1793.pdf
} 
Constitución: "El derecho de propiedad es el que pertenece a todo ciudadano para gozar y disponer libremente de sus bienes, rentas, industrias y el fruto de su trabajo". ${ }^{16}$ Por último, el artículo 19 prohibió que se privara a un ciudadano de sus bienes, salvo por razón de utilidad pública previa y legalmente acreditada y precedida de la justa indemnización. ${ }^{17}$

Esta Constitución resulta más compleja en cuanto a su análisis, ya que parte del principio de la propiedad en cuanto un derecho natural, lo que contradice la tesis jacobina de inspiración roussoniana acerca del tema. Luego, acreditó su contenido con la más amplia libertad posible y, como corolario, prohibió su expropiación. También resulta evidente que las condiciones han cambiado con respecto a 1791; ya no se habla de bienes nacionales -todos han sido ya vendidos- y ciertamente el contenido avanzado de la Constitución de 1793 no se evidencia en cuanto a la propiedad, pues su concepción siguió siendo eminentemente burguesa.

De esta manera, el liberalismo como corriente política nació en Cuba de la mano de la Ilustración, en las décadas postreras del siglo xvIII. Su aparición coincidió con el desarrollo económico y cultural que experimentó la isla desde mediados de la centuria y con la aparición de una élite criolla que impuso su visión sobre el futuro. En la historiografía cubana se ha resaltado la entrada, por primera vez, de un grupo de pensadores políticos y económicos autóctonos, que encauzaron el proceso reformista y abrieron el debate sobre cuál debía ser el futuro de Cuba.

En este contexto hace su entrada en la escena histórica cubana un cerrado y brillante grupo de hombres de pensamiento, la Generación del 92, o la Ilustración Reformista Cubana [...] pertenecientes a las más poderosas familias de la oligarquía criolla, educados dentro de las más modernas corrientes de pensamiento y formados bajo la experiencia mercantil y productora, se caracterizan por una amplia cultura enciclopédica, una coherente concepción socioeconómica, una activa participación en las esferas de poder, tanto peninsulares, como insulares, y una pragmática proyección política”. ${ }^{18}$

\footnotetext{
${ }^{16}$ Torremocha, Manuel, "Constitución francesa de 1793", ies Las Musas. [Consulta: 33 de enero, 2010]. Disponible en: www.ieslasmusas.org/geohistoria/constiticionfrancesa1793.pdf.

${ }^{17}$ Torremocha, Manuel, "Constitución francesa de 1793", ies Las Musas. [Consulta: 33 de enero, 2010]. Disponible en: www.ieslasmusas.org/geohistoria/constiticionfrancesa1793.pdf

${ }^{18}$ Torres Cuevas, Eduardo y Loyola Vega, Oscar, Historia de Cuba 1492-1898: Formación y liberación de la Nación, La Habana, Editorial Pueblo y Educación, 2002, p. 107.
} 
Cabe señalar que no se trató de un grupo homogéneo en cuanto a su pensamiento: para los iniciadores, como Francisco de Arango y Parreño, el objetivo era consolidar a una fuerte clase de terratenientes criollos, vinculados con el mercado internacional con productos de alta demanda, como el azúcar y el café, utilizando para ello la mano de obra esclava. Como señaló Santamaría García: "Su proyecto se impuso porque el crecimiento de la oferta azucarera, gracias a su ventaja comparativa y a la trata masiva de esclavos, reportó a las élites insulares y metropolitanas y al gobierno otras alternativas". ${ }^{19}$

$\mathrm{Al}$ respecto, no puede obviarse que dicho proyecto "confirió a la élite habanera el poder político que demandaba, que no fue ni mucho ni poco, sino mayor que el que tuviera en cualquier otro momento de su historia..$^{20}$ Este éxito resultó efímero. Para la década de 1830, el comercio de origen peninsular controló la vida económica de la isla y los desplazó del poder político. ${ }^{21}$ Como señaló Roldán de Montaud:

Muchos de los comerciantes establecidos en la Isla habían logrado labrar cuantiosas fortunas al amparo del tráfico, convirtiéndose en uno de los grupos más influyentes. Un puñado de ellos, la camarilla del general Tacón, llegó a tener en los años treinta un enorme poder, imponiendo sus decisiones en Madrid. A esas alturas, la oligarquía criolla, que había dominado todas las esferas de la vida cubana era decididamente postergada en la vida política local y perdía su poder en la capital de la monarquía. ${ }^{22}$

A finales del período, comenzó una nueva corriente de pensamiento propugnada por el obispo Juan José Díaz de Espada y Fernández de Landa, quien defendió la pequeña propiedad agrícola contra el latifundio y pidió la abolición de la esclavitud. Su actuación no sólo procuró el mejoramiento del estado espiritual y material de su grey, sino también la defensa de los intereses de la Iglesia. Como señaló Fernández Mellén: "En un contexto general de reforma del clero y

\footnotetext{
${ }^{19}$ Santamaria Garcia, Antonio y Vázouez Cienfuegos, Sigfrido, "El Discurso de Arango en su contexto histórico", en Juan Bosco Amores Carredano, Los tiempos de Espada: Vitoria y La Habana en la era de las revoluciones atlánticas, España, Universidad del País Vasco, 2014, p. 254.

${ }^{20}$ Santamaria Garcia, Antonio y Vázouez Cienfuegos, Sigfrido, "El Discurso de Arango en su contexto histórico", en Juan Bosco Amores Carredano, Los tiempos de Espada: Vitoria y La Habana en la era de las revoluciones atlánticas, España, Universidad del País Vasco, 2014, p. 291.

${ }^{21}$ Santamaria Garcia, Antonio y Vázouez Cienfuegos, Sigfrido, "El Discurso de Arango en su contexto histórico", en Juan Bosco Amores Carredano, Los tiempos de Espada: Vitoria y La Habana en la era de las revoluciones atlánticas, España, Universidad del País Vasco, 2014, p. 264.

${ }^{22}$ Roldán de Montaud, INÉS, La Restauración en Cuba. El fracaso de un proceso reformista, Madrid, Consejo Superior de Investigaciones Cientificas - Centro de Humanidades - Instituto de Historia, 2000, p. 1.
} 
del sistema beneficial que impulsó la monarquía desde las últimas décadas del siglo xvIII, Díaz de Espada acometió una profunda reforma de la organización beneficial, que fue complementaria a la reforma de la estructura eclesiástica y que fue la más importante y ambiciosa reorganización que conoció la Iglesia insular a lo largo de los tres siglos coloniales". ${ }^{23}$

No obstante, este discurso Ilustrado, más allá de sus diferencias en cuanto al futuro de la isla, presentó algunos elementos coincidentes. En primer lugar, estaba su deseo de modernizar Cuba siguiendo las pautas del desarrollo capitalista, entonces pujante en los centros de poder europeos. Este afán se tradujo en el estudio de la economía política y la profunda preocupación por la reforma de los programas de estudio universitarios, lo que permitió la introducción de asignaturas como Química y Botánica y la entrada de la vacuna contra la viruela, entre otras medidas de significativa importancia. Un segundo punto en común era la progresiva aceptación de la teoría de los derechos naturales del hombre, entendidos a la luz del prisma del pensamiento europeo y norteamericano.

En este sentido, la propiedad constituyó uno de los principales temas donde coincidían los afanes modernizadores y las teorías acerca de los derechos del hombre. De hecho, el vocero más caracterizado de este grupo, Arango y Parreño, en su calidad de consejero de Indias, señaló "Aquel luminoso principio [...] que deposita y asegura la riqueza y propiedad de las naciones, en el uso libre de los derechos de propiedad". ${ }^{24}$

Para los liberales cubanos, la propiedad resultó ser, al igual que para los teóricos europeos, un derecho esencial del hombre de carácter imprescriptible, y debía primar sobre el resto, una vez que se pusieran en la balanza. De esta forma, siguiendo a Locke: "la finalidad máxima y principal que buscan los hombres al reunirse en Estado es la salvaguarda de sus bienes”. ${ }^{25}$ El carácter de la propiedad como derecho rector, superior al resto de los reconocidos, se reforzó por la existencia y permanencia en Cuba de la esclavitud. Con ello se creó la paradoja de que la libertad individual quedara subordinada a la propiedad individual. De esta manera, como ha señalado Fernández Viciedo:

El triunfo final de sus defensores - quienes habrían de poner a su servicio todo el arsenal teórico elaborado por el racionalismo ilustrado, y que en Europa se usó para fundamentar los derechos individuales

\footnotetext{
${ }^{23}$ Fernández MelLén, Consolación, "En mejor servicio de Dios y del Rey: El obispo Espada y la reforma eclesiástica de la iglesia habanera", en Juan Bosco Amores Carredano, Los tiempos de Espada: Vitoria y La Habana en la era de las revoluciones atlánticas, España, Universidad del País Vasco, 2014, p. 151.

${ }^{24}$ Sagra, Ramón de la, Cuba 1860. Selección de Artículos sobre agricultura cubana, La Habana, unesco, 1963, p. 55.

${ }^{25}$ LOCKE, JoHn, Ensayo sobre el gobierno civil, Buenos Aires, Aguilar, 1960, p. 142.
} 
del hombre, determinó que en nuestros orígenes constitucionales, el pensamiento esclavista criollo, antepusiera, al derecho a la libertad, el "sagrado" derecho de propiedad. ${ }^{26}$

Asimismo, debe mencionarse el primer debate serio acontecido en las Cortes Constituyentes de Cádiz 1810, pues resultó un significativo ejemplo de esta tendencia. En dichas cortes se produjo el primer choque en materia doctrinal: un grupo de diputados españoles y americanos quisieron llevar a la libertad individual hasta sus últimas consecuencias, pidiendo la abolición de la esclavitud. Sin embargo, los representantes de Cuba abandonaron sus postulados liberales para oponerse a la medida que directamente perjudicaba sus intereses.

En esas circunstancias, asumieron la única línea de defensa posible, utilizando como argumento que, si la propiedad era un derecho sagrado e inviolable, no podía atacarse la de los hacendados cubanos, legítimamente obtenida. Frente al interés de la libertad y del humanitarismo, los representantes de la isla opusieron el de la propiedad, reconocido por constituyentes como Argüelles, quien refirió que "Libertad, igualdad y propiedad son los derechos naturales dados por Dios que los hombres deben proteger cuando entran en sociedad". ${ }^{27}$

Arango y Parreño, ${ }^{28}$ a nombre del cabildo habanero, adoptó una postulación más inteligente, utilizando un argumento muy en boga en las doctrinas liberales de la época, al afırmar el carácter sagrado de la institución: "Puede ponerse la mano en el sagrado de la propiedad, ya adquirida en conformidad de las leyes; de la propiedad decimos, cuya inviolabilidad es uno de los grandes objetos de toda asociación política, y uno de los primeros Capítulos de toda Constitución".

Igualmente, se opone a las propuestas de José Miguel Guridi y Alcocer que implicaban una limitación excesiva de las facultades dominicales, al "hacer una novedad capital en el ejercicio del dominio ya adquirido en los siervos introducidos, quitando la facultad de poder venderlos o pasarlos a otras manos". ${ }^{29}$ Esta posición se mantuvo prácticamente hasta la abolición de la esclavitud en 1886. Es dable destacar que importantes sectores del liberalismo cubano defendieron la primacía de la libertad por encima de la propiedad. El obispo

\footnotetext{
${ }^{26}$ Fernández Viciedo, Yuri, "Los 'fieles' origenes del constitucionalismo cubano", en Carlos Villabella Armengol (comp.), Hitos constitucionales del siglo xix cubano, México, Instituto de Ciencias Jurídicas, 2011, pp. 62-63.

${ }^{27}$ Carr, Raymond, España: 1808-1939, Barcelona, Ariel, 1969.

${ }^{28}$ Arango y Parreño, Francisco, Obras completas, vol. 2, La Habana, Imagen Contemporánea, 2005, p. 23.

${ }^{29}$ Arango y Parreño, Francisco, Obras completas, vol. 2, La Habana, Imagen Contemporánea, 2005, pp. 23 y 44.
} 
Espada $^{30}$ consideró a la esclavitud como una institución social nociva que era preciso erradicar, pensamiento que coincide también con el de Félix Varela, quien propuso el primer proyecto integral de abolición. Asimismo, José Antonio Saco abogó por suprimirla paulatinamente y, al mismo tiempo, blanquear la isla, pues para este autor la raza negra era el mayor enemigo de la nación cubana.

De hecho, partiendo del análisis anterior podemos identificar en el liberalismo cubano dos corrientes fundamentales: la primera, de corte conservador, que defendió la supremacía de la propiedad sobre el resto de los derechos en especial lo referente a la esclavitud y su uso como barrera a la hora de conceder derechos políticos; la segunda, que se inclinó por anteponer la libertad sobre la propiedad y de reclamar igualmente el sufragio universal. Más allá de estas diferencias, ambas coincidían en su carácter de derecho fundamental y en la necesidad de su protección constitucional.

\section{El impacto de la propiedad en el constitucionalismo español del siglo XIX en Cuba}

La historia del políticamente convulso siglo XIX español está salpicada de rebeliones, golpes de Estado y cambios constitucionales. Puede decirse -sin ninguna duda- que el rasgo esencial de la sociedad española decimonónica y, en consecuencia, de su derecho constitucional, fue la inestabilidad. La debilidad de la burguesía peninsular para hacer frente a las fuerzas del Antiguo Régimen y con posterioridad a 1837 las discordias internas en su seno, produjeron una gran inestabilidad política que se trasladó al plano constitucional. En el siglo xIx hubo en España ocho textos constitucionales, la mayoría redactados durante su primera mitad: el Estatuto o Constitución de Bayona de 1808, la Constitución de Cádiz de 1812, el Estatuto Real de 1834, la Constitución de 1837, la Constitución de 1845, la Constitución de 1856, la Constitución de 1869 y la Constitución de 1876.

De estas constituciones, la de Cádiz estuvo vigente en tres ocasiones (1812-1814, 1820-1823, 1836-1837). La Constitución de 1845 y sus múltiples modificaciones resultaron -en sentido general- revisiones más conservadoras de la del texto de 1837, al ampliar los poderes del monarca y favorecer la formación de un Senado vitalicio, similar a la Cámara de los Lores inglesa. La Constitución de 1876 -última del siglo- inauguró un período de estabilidad constitucional, que duraría hasta 1921.

${ }^{30}$ Diaz de Espada y Fernández de Landa, Juan José, Papeles, La Habana, Editorial Imagen Contemporánea, 2005, p. 210. 
La evolución constitucional de España durante el siglo XIX puede dividirse en dos corrientes fundamentales, separadas por matices importantes, si bien a ambas les informa la misma ideología liberal burguesa. Varela Suanza señala:

A este respecto, es sólito distinguir dos modelos: uno progresista, plasmado en las Constituciones de 1812,1837 y 1869, y otro conservador, recogido en las Constituciones de 1834, 1845 y 1876. Si en efecto, las Constituciones progresistas partían de la soberanía nacional y de un concepto racional normativo de Constitución, las moderado conservadoras partían de la soberanía compartida entre el Rey y las Cortes y de un concepto histórico de Constitución. ${ }^{31}$

Es por ello que debemos distinguir en su seno estas dos modelos: en primer lugar, el constitucionalismo moderado que informó los magnos textos de 1834 con sus reformas, el de 1845 con sus modificaciones y el proyecto de Bravo Murillo de 1852. En segundo lugar, la vertiente progresista representada por la Constitución de 1837, la non nata de 1856 y la efímera de 1869. Al margen de ambas corrientes encontramos el Estatuto de Bayona de 1808; la Constitución de Cádiz $^{32}$ de 1812, los proyectos republicanos de 1873 y la Constitución de 1876.

Pese a estos reiterados cambios -en lo que nos interesa en esta investigación- la constitucionalización de la propiedad constituyó un elemento constante en los mismos, y, en sentido general:

Las seis constituciones vigentes durante el siglo XIX reconocían un conjunto de derechos individuales, concebidos como ámbito de autonomía del individuo (y de la sociedad como conjunto de individuos) frente a las administraciones públicas. Un reconocimiento que se hacía a partir del principio de igualdad ante la ley, prius lógico de todos los demás derechos, ya fuesen los de propiedad -convenientemente desamortizada y desvinculada-, los de libertad personal o los de seguridad. ${ }^{33}$

\footnotetext{
${ }^{31}$ Varela Suanza Carpegna, Joaquin, "La construcción del Estado en la España del siglo XIX. Una perspectiva constitucional", en Carlos Manuel Villabella Armengol, (comp.), Hitos constitucionales del siglo xix cubano, México, Instituto de Ciencias Jurídicas de Puebla, 2011.

${ }^{32}$ Las circunstancias especiales de su elaboración, y el inevitable enfrentamiento ideológico con el absolutismo hicieron que este primer fruto español del pensamiento liberal fuera más allá de lo que ambos partidos -no escindidos todavia - estaban dispuestos a conceder. Aunque después sirvió de bandera de lucha contra el despotismo monárquico, era demasiado liberal y democrático para su gusto. De ahi que, aunque los debates en torno a la misma provocaron la división en el seno liberal, ambos coincidieron en que era inaplicable, y era necesario sustituirla.

${ }^{33}$ Varela Suanza Carpegna, Joaquín, "La construcción del Estado en la España del siglo xix. Una perspectiva constitucional", en Carlos Manuel Villabella Armengol, (comp.), Hitos constitucionales del siglo xIx cubano, México, Instituto de Ciencias Jurídicas de Puebla, 2011, p. 15.
} 
Pese a estos reiterados cambios, la presencia de la propiedad resultó en estos cambios un elemento constante y esencial aunque su regulación no fuera homogénea.

No obstante, es dable destacar que todos los textos constitucionales señalados partieron de los supuestos teóricos ya reconocidos por la doctrina europea acerca de la propiedad como derecho. En primer lugar, se debe atender a la presencia o no del derecho dentro del articulado constitucional. En tal sentido, sólo las constituciones de 1812, la tabla de derechos que debía añadirse al Estatuto Real de 1834 y los proyectos republicanos federales de 1872-1873 la incluyeron como un derecho efectivo, limitándose el resto a consignar las garantías necesarias para su protección. Por supuesto, ello no quiere decir que la propiedad como institución no fuera un elemento esencial dentro del pensamiento liberal español y de su ordenamiento jurídico, como se verá a continuación.

Con respecto a las formas de garantizar este derecho, el constitucionalismo español fue más abundante. Aparecen de una forma u otra en casi todos los textos de la etapa. Se debe considerar dentro de estas garantías la prohibición al Gobierno de despojar a un individuo de su patrimonio, regla general que se estableció a partir de la Constitución de 1812 y que se mantuvo en todos los textos y proyectos constitucionales estudiados, con la salvedad de los Estatutos de Bayona y los de 1834, ya que eran consideradas como un atentado a las prerrogativas monárquicas y se excluyó por consideraciones de política práctica.

La Constitución de 1812 estableció la garantía señalada en el artículo 72, ordinal 10 y como complemento necesario reguló también la institución de la expropiación forzosa, mediante la cual era posible privar a un individuo de sus bienes, ejecución que quedó a cargo de la administración pública. Iguales garantías fueron otorgadas por la tabla de derechos propuesta para complementar al Estatuto Real y también en el proyecto de la Isabelina, en las modificaciones al Estatuto propuestas por el Consejo de Ministros y en la Constitución de 1837.

Durante el período de 1837 a 1868, el gobierno estuvo bajo el control de los moderados, por lo que el constitucionalismo español mantuvo fórmulas similares. La Constitución de 1845 en su articulado conservó intacta la regulación de la Constitución de 1837, y los proyectos de modificaciones de 1852 y 1853 siguieron sus pasos. Sin embargo, en el caso del proyecto de 1852, se produjo una importante alteración al ser extraídos los derechos de la Constitución y traspasados a una Ley Orgánica ${ }^{34}$ adjunta al proyecto, lo que suponía menos

${ }^{34}$ Sevilla Andrés, Diego, Constituciones y otras leyes y proyectos políticos de España, tomo 1, Madrid, Editora Nacional, 1969 , p. 423. 
garantías para esta institución. La Constitución nonata de $1856,{ }^{35}$ fruto del bienio progresista, dispuso una regulación similar al resto de las constituciones españolas en este tema.

En la Constitución de 1869 se incluyó una formulación parecida, aunque introdujo una importante novedad al hacer responsables a los funcionarios públicos por la infracción del artículo 13. Los textos republicanos asumieron una postura semejante pero la Constitución de 1876 volvió a las fórmulas tradicionales del período anterior a 1868 y en su artículo 10 se restableció de esta forma el sistema de expropiación por vía administrativa, sin respaldo judicial.

Otra garantía incluida en el constitucionalismo español decimonónico fue la prohibición de la confiscación de bienes. Respecto a ella, pueden apreciarse dos tendencias fundamentales: aquéllos textos constitucionales que no la incluían en su articulado, como el de Bayona y el Estatuto Real de 1834 y el proyecto de bases republicanas de 1872, el resto de los textos estudiados lo incluyó dentro de su articulado, sobre todo en la parte dogmática, cuando en realidad no era más que una garantía para el derecho. La explicación de esta doctrina radicó en el deseo de proteger a la propiedad de los abusos de los funcionarios judiciales que se adueñaban de los bienes bajo diversos pretextos, aún sin haber terminado el proceso.

Asimismo, la Constitución de Cádiz inició una tendencia al incluir la confiscación de bienes dentro de las penas prohibidas por la ley, en su artículo 304. $\mathrm{Su}$ forma de regularlo resulta muy interesante, ya que se estableció como un límite específico a la autoridad judicial, no sólo por su redacción sino por incluirse en la sección dedicada a la administración de justicia. El proyecto de reformas al Estatuto Real mantuvo el mismo criterio en su artículo 48 y el resto de las constituciones elaboradas en la época lo trasladaron al título donde se recogieron los derechos de los españoles, aunque se utilizó una fórmula muy similar.

La Constitución de 1869 modificó la práctica anterior, al ampliar el contenido de esta garantía y, paradójicamente, reintroducir la confiscación de bienes para la sede penal en su artículo 13. Los proyectos republicanos de 1873 continuaron por el sendero abierto por el texto de 1869. Sin embargo, la Constitución canovista de 1876 restableció el orden de cosas existente en este tema con anterioridad al sexenio revolucionario, ya que en su artículo 10 volvió a la redacción tradicional.

Otro aspecto es el problema de los impuestos, considerados como una forma de privar al individuo de sus bienes. Dado que eran considerados como un aporte

\footnotetext{
${ }^{35}$ Castillo Alonso, Gonzalo del, Constitución del Estado, p. 610.
} 
al sostenimiento del Estado, se va a procurar rodearlo de ciertas garantías para que no degenere en los abusos del Antiguo Régimen, tal y como lo plantearon los diputados gaditanos en 1812. Según acotó un autor decimonónico:

El Gobierno, para atender a las cargas públicas y garantizar al individuo su propiedad particular, exige de éste una parte de esa misma propiedad y por esto se llama contribución; mas, para que el Estado no pueda abusar de los contribuyentes, y éstos puedan tener un dato cierto acerca de los gravámenes que pesan sobre sus bienes, se ha establecido que no se imponga ni cobre ninguna contribución ni arbitrio que no esté autorizado por la ley de presupuestos. ${ }^{36}$

El tema resultó recurrente a lo largo del siglo xIX y el constitucionalismo español lo reguló de la única forma posible, considerándolo un deber del ciudadano sujeto a ciertas garantías: el reconocimiento de que nadie está obligado a pagarlas si no han sido legalmente establecidas; en segundo lugar, sólo el órgano legislativo como representante de la nación está facultado para aprobarlos, oídos los informes pertinentes y suscitándose el debate en torno hasta dónde debían participar.

Hasta aquí nos encontraremos con dos tendencias fundamentales: una, representada por los textos de Bayona, 1834, el proyecto de Juan Bravo Murillo y las reformas a la Constitución de 1845 presentadas en 1853, que buscaron limitarla todo lo posible; otra, vinculada con los cuerpos normativos de 1812, el proyecto de la Isabelina, 1837, 1845, 1869, y la de 1876, que trataron de darle al legislativo amplio control en esta materia. Como consecuencia, quedó reconocido el deber para los ciudadanos españoles de pagar contribuciones, aunque sujetos a una serie de garantías y mecanismos destinados a salvaguardar la propiedad privada. Muy vinculado con el tema anterior se encuentra lo relativo a la participación en el poder político por parte de la burguesía, a través de los mecanismos electorales. De esa forma, según Azcárate:

Ha aparecido una nueva relación entre la propiedad y el derecho político en la regulación del sufragio por el censo [...] en el cual puede pretenderse aunque sin razón, que es un signo de capacidad para el ejercicio de la función electoral, en cuyo caso no adolece de ese vicio, pero que en realidad de verdad se ha establecido para constituir con los propietarios un núcleo de resistencia en el seno de las sociedades,

\footnotetext{
${ }^{36}$ Dánvila, Manuel, El Libro del propietario, Valencia, Imprenta de José Rius Editor, 1862, p. 544.
} 
constituyéndolos en como clase basada en la riqueza y análoga a la de los tiempos antiguos. De esta forma: Fue así como se conformó como el pilar sobre el que se sostenía la sociedad a causa, precisamente, de la definitiva proyección que alcanzaba no sólo en el ámbito privado de los particulares sino en el público, al ser el único baremo que las primeras Constituciones consideraron para otorgar la titularidad y el ejercicio de los derechos políticos. ${ }^{37}$

Durante el siglo XIX se manifestaron al respecto tres tendencias en el constitucionalismo español: una corriente moderada que buscó limitarlo lo más posible, de tal manera que el mismo se convirtiera en un privilegio como en el Estatuto de Bayona, el Estatuto Real de 1834 y las constituciones de 1845 y 1876; en segundo lugar, los progresistas que, sin defender el sufragio universal, aspiraron a ampliarlo lo más posible para dar cabida a la clase media e intelectual, como se evidenció en los textos de 1812, 1837 y 1856; y una tercera escuela, la demócrata, presente en la constitución de 1869 y en los proyectos republicanos que aspiró al ejercicio universal de este derecho. No obstante, las fuerzas políticas más importantes del siglo XIX español resultaron coincidentes en cuanto a la necesidad de restringirlo. Como ha señalado una autora:

No es, en este sentido, superfluo recordar una vez más que la libertad política, a diferencia de la civil [...] se había erigido como el fundamento jurídico del sufragio, de los derechos políticos, y de ella sólo disfrutaban propietarios y rentistas. De esta manera, la propiedad se convirtió [...] De hecho, es la piedra angular sobre lo que se construye el edificio constitucional con su diferencia entre españoles y ciudadanos españoles. ${ }^{38}$

Como se ha podido apreciar, el constitucionalismo español reconoció a la propiedad como un elemento fundamental del orden social y procuró otorgarle las mayores garantías constitucionales posibles. Se utilizó también como medidor en el otorgamiento de derechos políticos.

La historia constitucional de Cuba se inició en el siglo XIX con los textos españoles que se aplicaron en la isla: la Constitución gaditana de 1812, el Estatuto Real de 1834 y la Constitución de 1876. Con respecto a la propiedad, pese a las

\footnotetext{
${ }^{37}$ Álvarez, ClarA, "El Estado en cuestión: Cuba y la esclavitud en las Cortes de Cádiz", en Antonio Filiú Franco y Clara Álvarez Alonso, La Cuestión cubana en las Cortes de Cádiz, Madrid, Fundación Coloquio Jurídico Europeo, 2011, p. 162.

${ }^{38}$ Álvarez, Clara, "El Estado en cuestión: Cuba y la esclavitud en las Cortes de Cádiz", en Antonio Filiú Franco y Clara Álvarez Alonso, La Cuestión cubana en las Cortes de Cádiz, Madrid, Fundación Coloquio Juridico Europeo, 2011, p. 168.
} 
diferencias entre criollos y peninsulares, en el fondo ambos eran deudores del mismo pensamiento liberal burgués heredado de la Revolución francesa, aunque el mismo se encontraba muy atenuado a ambos lados del Atlántico.

La extensión a Cuba del catálogo de derechos del texto doceañista tuvo más o menos la misma significación que para España: los cubanos no podrían ser despojados de su propiedad sino en caso de utilidad pública y previa indemnización; se prohibía la confiscación de bienes y se les llamaría para que, a través de sus diputados, participaran en el proceso de aprobación de los impuestos. Esto supuso su primera experiencia en las prácticas parlamentarias. El Estatuto Real de 1834 carecía de carta de derechos, por lo que no se reconocían garantías jurídicas específicas a la propiedad; no obstante, los cubanos participaban a través de representantes en la votación de los impuestos, lo que era una garantía mínima en este campo.

A partir de 1837, al quedar excluida del régimen constitucional español, se perdieron las garantías que ofrecía a la propiedad el liberalismo constitucionalizado. Lo anterior no quiso decir que se produjera un caos jurídico y que la institución no fuera amparada por las autoridades, aunque sus defensas resultaron insuficientes. ${ }^{39}$

No obstante, partiendo del discurso lógico del liberalismo, el gobierno metropolitano se convirtió en el garante de la institución. Ello explica la preocupación de sus funcionarios por la política de tea incendiara aplicada por los separatistas. El capitán general de Cuba, Joaquín Jovellar, lo expresó con franqueza propia del soldado: "se vio la propiedad entera amagada [...] y las propiedades el sostén principal de nuestra causa por ser los intereses que a ella liga y por ser la fuente de nuestros recursos". ${ }^{40}$ Ello no impidió el establecimiento de un masivo proceso confiscatorio que despojó a la élite criolla de sus bienes y terminó con su venta o remate, por la insistencia de los sectores españolistas. En este sentido, Roldán de Montaud firma lo siguiente:

A partir de agosto de 1870 se autorizó al gobierno a cubrir, previa consulta al Consejo de Estado, los gastos de la guerra no sólo con el producto de los bienes como hasta entonces, sino también con el valor de las propiedades. Para ello era necesaria primeramente una sentencia de

\footnotetext{
${ }^{39}$ Lo anterior se hizo evidente en el delicado tema de la expropiación forzosa donde hasta 1841 hubo cierto vacío normativo. En esa fecha, un Real Decreto de la Regencia hizo extensiva la Ley de 1836, con modificaciones en cuanto al procedimiento. Si bien ello puede reputarse un avance en el otorgamiento de garantías, el capitán general conservó la atribución de poder expropiar a su arbitrio. MoRRILLA, José MARí, Breve tratado de Derecho administrativo español general del Reino y especial de la isla de Cuba, La Habana, Sin editor, 1847, pp. 260-263.

${ }^{40}$ Rodriguez, Rolando, Cuba: la forja de una nación, La Habana, Editorial de Ciencias Sociales, 2005, p. 347
} 
los tribunales declarando a los sujetos embargados preventivamente reos del delito de rebelión y responsables de los daños causados al Estado o a los particulares. ${ }^{41}$

Como consecuencia: "La guerra aceleró el proceso de concentración de fincas agrícolas en manos peninsulares". ${ }^{42}$ Con ello, se terminó el proceso de destrucción de la clase dirigente de la sociedad cubana, permitiendo su progresivo reemplazo por el capital español y foráneo, con graves consecuencias para el futuro de Cuba.

El establecimiento en la isla de la Constitución de 1876 dio inicio a una nueva etapa constitucional, con la aplicación de su catálogo de derechos que incluía al de propiedad. Durante la misma, se utilizó como norma reguladora del sistema electoral el texto metropolitano, con ajustes para el contexto antillano y se introdujeron dos novedades muy significativas: la primera de ellas con la creación de la ley electoral, cumpliendo una disposición transitoria de la Constitución; la segunda, la creación de un censo electoral diferente para el caso cubano, en beneficio de los sectores integristas.

En consecuencia, la implementación en Cuba del constitucionalismo español a lo largo del siglo XIx, si bien otorgó ciertas garantías a los cubanos en lo referente a la propiedad, resultó insuficiente por su carácter esporádico y limitado.

\section{La visión liberal de la propiedad en los antecedentes del constitucionalismo cubano del siglo $\mathrm{XIX}$}

En sentido general, la propiedad en Cuba careció durante buena parte del siglo XIX de protección constitucional y cuando la hubo esta resultó insuficiente, ya que contrariaba los intereses metropolitanos. Por ello, no resulta extraño que los cubanos buscaran ponerle remedio a esta desfavorable situación incluyéndola en sus propios proyectos constitucionales. En primer lugar, es necesario aclarar que no existió homogeneidad en cuanto a los objetivos

196 perseguidos por las diferentes fuerzas políticas locales durante el siglo XIX ${ }^{43}$ esto es especialmente notable en el tema de la propiedad, puesto que hasta 1868 existió un fiero debate entre defensores y detractores de la esclavitud, tema que giró en torno al binomio propiedad-libertad.

\footnotetext{
${ }^{41}$ Roldán dE MontAUd, INÉS, La Restauración en Cuba. El fracaso de un proceso reformista, Madrid, Consejo Superior de Investigaciones Científicas - Centro de Humanidades - Instituto de Historia, 2000, p. 101.

${ }^{42}$ Roldán de Montaud, InÉs, La Restauración en Cuba. El fracaso de un proceso reformista, Madrid, Consejo Superior de Investigaciones Científicas - Centro de Humanidades - Instituto de Historia, 2000, pp. 97 y 98.

${ }^{43}$ Tradicionalmente se les divide en reformistas, autonomistas, separatistas y anexionistas.
} 
En consecuencia, nos referiremos en este acápite a los proyectos de José Agustín Caballero, Gabriel Claudio de Zequeira, Félix Varela, el atribuido a Calixto Bernal, publicado en la Revista Hispanoamericana en 1865, los presentados en respuesta al cuestionario político en la Junta de Información de 1866-1867, el de Calixto Bernal de 1881, el que expusieran los diputados del Partido Liberal Autonomista en el Congreso de los Diputados durante la legislatura de 1886, el de Joaquín Infante, Narciso López y la sociedad “Ave María”.

Los proyectos constitucionales elaborados por los reformistas a lo largo del siglo xIX tuvieron una peculiaridad distintiva al tratar el tema de la propiedad, pues esta institución no aparece regulada en los mismos, salvo en dos excepciones. En nuestra opinión, esto se debió a dos motivos fundamentales: en primer lugar, una parte importante de los mismos fueron elaborados durante la vigencia en Cuba de constituciones españolas, con su catálogo de derechos y garantías, entre los cuales se incluía a la propiedad -de ahí que sus autores no creyeran necesario incluirlos en sus obras, puesto que bastaba con aplicar lo preceptuado en la normativa ibérica, para tenerlos establecidos y garantizados-. A lo anterior, hay que sumar la idea bastante común entonces de que se trataba de derechos naturales imprescriptibles, comunes al género humano, y que para su ejercicio en Cuba no había que formularlos nuevamente. En este sentido, sólo los proyectos presentados a la Junta de Información incluyeron una carta de derechos; el resto se limitó a las cuestiones vinculadas con el tema tributario y el ejercicio del sufragio.

Por consiguiente, se puede concluir que los proyectos autonomistas, al regular el derecho de la propiedad, no lo desarrollaron como en el constitucionalismo europeo y norteamericano, pues salvo por dos excepciones no se incluyó la institución dentro de un catálogo de derechos del que además carecían. En tal sentido, se suponía aplicable la normativa de los textos españoles como mecanismo para solventar esta falta. No obstante, sí procuraron proteger al derecho de propiedad estableciendo un control local sobre los impuestos y confiando a una asamblea legislativa local la facultad de aprobar el presupuesto y de establecer los impuestos para cubrirlo, cumpliéndose de esta forma el principio de que sólo se podían cobrar aquellos que hubieran sido debidamente aprobados por la representación nacional. Por último, el vínculo entre la propiedad y el sufragio resultó palpable en estos textos, ya que se establecieron los requisitos de posesión de riqueza como barreras electorales para su ejercicio.

En el caso de los proyectos separatistas, hay que resaltar que partieron de un supuesto común, ya que al repudiar el régimen colonial no podían apoyarse en su derecho constitucional. Al respecto, se debe resaltar que, a la usanza de la época, se reconoció a la propiedad como un derecho fundamental 
y se trató de dotarla de la mayor cantidad de garantías posibles, compatibles con la situación de guerra. Si se compara estos proyectos con los reformistas estudiados, podemos concluir que ambas corrientes coincidieron en la necesidad de reconocer y consagrar el derecho de propiedad como un elemento esencial del orden social.

La guerra de independencia contra España (iniciada por Carlos Manuel de Céspedes el 10 de octubre de 1868) marcó el inicio de un proceso de profundas transformaciones en todos los aspectos de la sociedad cubana. ${ }^{44}$ Por ello, en el constitucionalismo revolucionario del período 1868-1898 se evidencia su carácter radical, no sólo por su rompimiento con España y por su aspiración de crear un Estado independiente, sino por su solución al problema de la esclavitud, que afectaba al derecho de propiedad y la necesidad del establecimiento del sufragio universal.

El manifiesto del 10 de octubre, redactado por Carlos Manuel de Céspedes, constituyó un reflejo de sus concepciones acerca de la propiedad. Defendía la idea de la propiedad como un derecho natural y, más adelante, como una declaración de principios. ${ }^{45}$ En defensa de este criterio, se adoptaron disposiciones jurídicas encaminadas a su defensa durante los años 1868 y 1869.

La Constitución de Guáimaro recogió en su articulado los derechos fundamentales en su precepto 28 , sin incluir entre ellos a la propiedad. ${ }^{46}$ No obstante, la ambigua fórmula utilizada puede entenderse en cualquier sentido. Al respecto, Ponte Domínguez consideró que "En la parte dogmática se fijó el estatuto de libertad de los ciudadanos; es decir: el límite de acción del gobierno como representante del Estado, estipulando los derechos individuales" ${ }^{47}$ Pese a lo dicho anteriormente, aparecen en este texto algunas medidas para proteger el derecho de propiedad, sobre todo en materia tributaria. Empero, el artículo 24, al declarar la abolición de la esclavitud sin indemnización, supuso de hecho una expropiación forzosa y un ataque al derecho de propiedad. ${ }^{48}$ En cuanto al vínculo con la participación política, el texto se pronunció por el sufragio universal masculino como expresión de su ideología democrática.

La Constitución de Jimaguayú no incluyó en su articulado los derechos y garantías fundamentales, pero la propiedad estuvo presente de varias formas,

\footnotetext{
${ }^{44}$ Carbonell Rivero, Néstor, Guáimaro 10 de abril de 1869-10 de abril de 1919. Reseña histórica de la primera Asamblea Constituyente y primera Cámara de Representantes de Cuba, La Habana, Imprenta de Seoane y Fernández, 1919.

45 "Respetamos las vidas y propiedades de todos los ciudadanos pacificos, aunque sean los mismos españoles". Pichardo, H., Documentos para la Historia de Cuba, t. I, p. 361.

${ }^{46}$ Pichardo, Hortensia, Documentos para la historia de Cuba, tomo 1, Cuba, Pueblo y Educación, 1984, p. 379.

${ }^{47}$ Ponte Dominguez, Francisco, Historia de la Guerra de los Diez Años. Desde su origen hasta la Asamblea de Guáimaro, La Habana, Imprenta El Siglo XX, 1944, p. 216.

${ }^{48}$ Pichardo, Hortensia, Documentos para la historia de Cuba, tomo 1, Cuba, Pueblo y Educación, 1984, p. 379.
} 
sobre todo en lo relativo a las contribuciones y la política de guerra económica. ${ }^{49}$ La Constitución de La Yaya trató de dar solución a los conflictos internos que habían afectado a la guerra durante el período 1895-1897 y con respecto a los derechos y garantías fundamentales incluyó un título dedicado a su regulación, ${ }^{50}$ donde la propiedad no estaba incluida. Esto no quiere decir que se encontrara ausente del articulado constitucional, pues su presencia era bien visible en varios de sus artículos, sobre todo en lo referente a contribuciones y la deuda pública. En cuanto a la relación entre la propiedad y el derecho al sufragio, este texto lo reconoció universal.

En esencia, durante el siglo xIx el liberalismo cubano recogió la herencia de la propiedad como derecho fundamental, incluyéndola de forma fragmentaria e incompleta en sus propuestas constitucionales. No obstante, se expresaron divergencias en cuanto a su alcance y contenido, lo que se vio reflejado en los temas del sufragio universal y de la esclavitud.

La guerra hispano-cubano-norteamericana de 1898, que puso fin a la soberanía española sobre Cuba, estuvo, en sus orígenes, muy vinculada con la propiedad. El conflicto armado que se ventilaba en la isla desde 1895 había ocasionado importantes daños a la propiedad, afectando intereses económicos de nacionales y extranjeros. Como resultado de ello, el gobierno español recibió, sobre todo de Estados Unidos, diversas reclamaciones diplomáticas que cuestionaron su capacidad para defender la propiedad privada. De hecho, el motivo que condujo al Maine a su trágico destino estuvo vinculado con unos incidentes violentos en La Habana que obligaron al gobierno norteamericano a enviar el buque para proteger a sus ciudadanos y sus bienes en caso de que España resultara incapaz de hacerlo.

El tratado de paz de París firmado entre España y los Estados Unidos en diciembre de 1898 ofreció algunas garantías a las propiedades presentes en los territorios cedidos a Norteamérica. En este sentido, resultan de especial interés para el tema en cuestión los artículos 1, 8, 9 y 13. En el caso del 8, se dispuso el traspaso de las propiedades consideradas de derecho público del gobierno español al norteamericano; no obstante, su párrafo segundo incluyó una importante salvedad al proteger los derechos de los poseedores pacíficos de bienes de la provincia, el municipio, las instituciones religiosas o cualquier corporación o de cualquier persona natural o jurídica. Por su parte, el artículo 9 reconoció a los súbditos españoles el derecho a conservar sus derechos de propiedad sin que pudieran afectarlos las autoridades ocupantes y el artículo 13 amparó la

\footnotetext{
${ }^{49}$ Lazcano y Mazón, Andrés, Las Constituciones de Cuba, Madrid, Ediciones Cultura Hispánica, 1952, pp. 513 y 516.

${ }^{50}$ Lazcano y Mazón, Andrés, Las Constituciones de Cuba, Madrid, Ediciones Cultura Hispánica, 1952, pp. 520 y 521.
} 
propiedad artística y literaria española. Como garantías al derecho de propiedad de los españoles, el propio texto se limitó a otorgar acceso a los tribunales locales con los mismos derechos que los nativos. Por último, no debe olvidarse que el artículo 1, al otorgarle a Estados Unidos el estatus de potencia ocupante en Cuba, lo obligó de acuerdo con el derecho internacional, a proteger vidas y haciendas. ${ }^{51}$

Del articulado del Tratado se desprende la preocupación de las partes contratantes por salvaguardar los derechos de propiedad preexistentes, incluyendo los de los propios españoles, a los que se otorgó garantías especiales. Debe tenerse en cuenta que el propio documento buscó extender sus efectos hacia el futuro, pues dispuso en su artículo 16 que el gobierno norteamericano aconsejaría a las futuras autoridades cubanas el cumplimiento de las mismas obligaciones. ${ }^{52}$

\section{La constitución cubana de 1901, síntesis del pensamiento liberal cubano del siglo $\mathrm{XIX}$}

La primera constitución cubana del siglo xx, elaborada por la Convención Constituyente de 1901, fue un acabado producto del pensamiento liberal del siglo XIx. Como señaló al respecto Enrique Hernández Corujo, en el orden formal el constitucionalismo seguía, más o menos, los principios invariables del Estado liberal, individualista y de limitación al poder. ${ }^{53}$ En esencia, cómo acotó Orestes Ferrara: "El principio liberal del siglo XIX, latu sensu adaptado por la Constitución cubana de 1901, es distinto de cualquier otro practicado en el pasado. La palabra libertad [...] se refiere a la suma de derechos individuales, considerándolos al margen del Estado, y hasta contra el Estado". ${ }^{54}$

En buena medida, puede considerarse que en la primera constitución cubana se resumían los ideales del pensamiento liberal constitucional cubano del siglo XIX y de sus corrientes fundamentales. Los principios informantes de la Constitución de 1901 se basaron en nuestra tradición histórica y jurídica, pues como señalara el mencionado Hernández Corujo: "Podríamos señalar como principios filosóficos, que fundamentaron, la Constitución cubana de 1901, el

\footnotetext{
${ }^{51}$ Lazcano y Mazón, Andrés, Las Constituciones de Cuba, Madrid, Ediciones Cultura Hispánica, 1952, pp. 537 y 538.

${ }^{52}$ Lazcano y Mazón, Andrés, Las Constituciones de Cuba, Madrid, Ediciones Cultura Hispánica, 1952, p. 543.

${ }^{53}$ Hernández Corujo, Enrique, Los fundamentos históricos y filosóficos de la Constitución de 1901, La Habana, Editorial Lex, 1953, p. 9.

${ }^{54}$ FerRara, Orestes, Las ideas político sociales en las constituciones cubanas, Madrid, Talleres Tipográficos Marsinoa, 1945, p. 19.
} 
individualismo, supremacía de la individualidad; la limitación al poder público, limitación de poderes y mantenimiento del civilismo". ${ }^{55}$

La Constitución de 1901 fue, en palabras de Bravo Correoso, la extensión a Cuba del legado de las revoluciones francesa y la norteamericana. ${ }^{56}$ En materia de derechos, la Carta Magna, siguiendo las doctrinas liberales, reconoció esencialmente derechos individuales como fundamento del orden social y límite al poder del Estado. Al respecto, expresó Ferrara: "En Cuba, la primera Constitución [...] vio consignados en ella todos los preceptos que desde el derecho romano se han venido elaborando sobre [...] la propiedad inexpropiable, ni siquiera por razones de utilidad pública hasta pagar la indemnización debida". ${ }^{57}$

En materia económica, los principios liberales eran igualmente un dogma entre los convencionales. Al respecto opinó Juan Clemente Zamora: "Si la propiedad y la conquista de la felicidad son derechos correspondientes a aquella categoría que cae dentro de la esfera de autarquía individual [...] En consecuencia, el Estado ha de respetar el derecho absoluto de propiedad privada individual". ${ }^{58}$

En este sentido, la Constitución dedicó al tema de los derechos el título IV con los artículos del 11 al 42; los artículos 32, 33, y 34 reconocieron a la propiedad privada como uno de los derechos individuales fundamentales y le otorgaron una serie de garantías básicas, dotándola de una regulación claramente inspirada en el liberalismo europeo y norteamericano, donde la propiedad es esencialmente un derecho individual. De hecho, la denominada cuestión social que ya se encontraba en la palestra, no encontró acogida en los debates de los constituyentes. ${ }^{59}$

Tampoco hay diferencias destacables con respecto al constitucionalismo español previo, puesto que se protegió a la propiedad privada de todas las formas posibles contra la interferencia del Estado. Quizás en este sentido el artículo 33, al prohibir totalmente la confiscación de bienes, supuso un retroceso frente a textos más avanzados, como la Constitución española de 1869.

Igualmente, en consonancia con el ya citado artículo 34, el poder de crear nuevos impuestos o modificar los existentes recaía en el Congreso de la República;

\footnotetext{
${ }^{55}$ Hernández Corujo, Enrique, Los fundamentos históricos y filosóficos de la Constitución de 1901, La Habana, Editorial Lex, 1953, p.11

${ }^{56}$ Bravo Correoso, Antonio, Cómo se hizo la Constitución de 1901, La Habana, Imprenta y Papelería Rambla, Bouza y Cía, 1927, p. 29.

${ }^{57}$ FerRaRA, Orestes, Las ideas político sociales en las constituciones cubanas, Madrid, Talleres Tipográficos Marsinoa, 1945, p. 18.

${ }^{58}$ Zamora, Juan Clemente, Nuevas Orientaciones en materia constitucional, La Habana, Editorial Atalaya, 1939, p. 8.

${ }^{59}$ Bravo Correoso, Antonio, Cómo se hizo la Constitución de 1901, La Habana, Imprenta y Papelería Rambla, Bouza y Cía, 1927.
} 
al respecto, los artículos 59.2 y 8 le otorgaron la primacía a la hora de elaborar las leyes de presupuesto. Por tanto, sería el órgano legislativo conformado por la representación de los propios contribuyentes el que se encargaría de revisar el gasto público y decidir si los impuestos necesarios para cubrir los fondos eran convenientes y pertinentes.

Un tema también vinculado con la propiedad era el referente al derecho al sufragio, el cual motivó una de las más encendidas polémicas de la Convención Constituyente. ${ }^{60}$ El resultado fue una solución de compromiso: la Sección Segunda reconoció en su artículo 38 el sufragio universal, aunque a la hora de establecer los procedimientos electorales la voluntad de los ciudadanos quedaba considerablemente restringida. En este sentido, la introducción de los compromisarios sacados de los mayores contribuyentes para la elección de los senadores constituyó un arreglo entre las dos tendencias opuestas.

Como puede apreciarse, la Constitución de 1901 era coherente en su defensa de la propiedad, de acuerdo con los postulados liberales del siglo xIx; constituyó un texto de consenso entre las dos corrientes del liberalismo cubano. En la Constitución se defendió la propiedad privada como un derecho esencial, estableciéndose limitaciones al poder público para evitar su vulneración. Por su parte, la Enmienda Platt, impuesta como apéndice a la Constitución de 1901, ofreció a los propietarios garantías adicionales en su artículo 3. Disponía...

Que el Gobierno de Cuba consiente que los Estados Unidos puedan ejercitar el derecho de intervenir para la conservación de la Independencia cubana, el mantenimiento de un Gobierno adecuado para la protección de vidas, propiedad y libertad individual y para cumplir las obligaciones que con respecto a Cuba han sido impuestas a los Estados Unidos por el tratado de París y que deben ahora ser asumidas y cumplidas por el Gobierno de Cuba. ${ }^{61}$

Con ello, la protección al propietario establecido en la isla, fuera nacional o extranjero, quedó a cargo del gobierno de los Estados Unidos, lo cual se convirtió en un pretexto de intervención. Al mismo tiempo, impuso a Cuba el respeto a las condiciones del Tratado de París de 1898, incluyendo la referida a las personas y los bienes de los españoles y extranjeros residentes en la isla. Asimismo, el artículo 2 de la propia enmienda limitó la capacidad de endeudamiento de

\footnotetext{
${ }^{60}$ Bravo Correoso, Antonio, Cómo se hizo la Constitución de 1901, La Habana, Imprenta y Papelería Rambla, Bouza y Cía, 1927, pp. 34 y ss.

${ }^{61}$ Pichardo, Hortensia, Documentos para la historia de Cuba, tomo 1, Cuba, Pueblo y Educación, 1984.
} 
la futura república con base en su posible solvencia económica; ${ }^{62}$ con ello, se buscó garantizar a los tenedores de títulos de la deuda pública cubana contra posibles bancarrotas del Estado.

En buena medida, estas disposiciones crearon una situación anómala en el derecho de propiedad vigente en Cuba: en primer lugar, las garantías de la Constitución de 1901 eran de por sí muy amplias, si se les compara con los textos españoles y cubanos de la centuria precedente; a ello debe sumarse la influencia norteamericana que se convirtió en una garantía adicional para este derecho. No resultó extraño, pues, que en la futura historia de la etapa republicana fueran habituales los reclamos del gobierno norteamericano ante la inefectividad de las autoridades cubanas en el tema y los desembarcos de marines en aras de su protección.

\section{Conclusiones}

El liberalismo cubano asumió doctrinas vinculadas con los derechos naturales del hombre, coincidiendo en la necesidad de protegerla contra la intromisión del Estado en la esfera de actuación del propietario. No obstante, en el mismo se expresaron dos corrientes distintas: la primera defendía la propiedad como un derecho superior a los demás, expresado en su defensa de la esclavitud y del sufragio censitario; la segunda, la primacía de la libertad, expresada en la abolición de la esclavitud y el sufragio universal.

Por otro lado, el constitucionalismo español, más allá de las diferencias de partido, asumió igualmente la propiedad como una categoría esencial dentro de su derecho constitucional. Siendo consecuente con lo anterior, le otorgó un grupo esencial de garantías en el orden jurídico, en especial las relacionadas con proteger al propietario frente a las interferencias del Estado, en lo referente al tema tributario, de la confiscación de bienes y de la expropiación forzosa, así como un papel preponderante a la hora de otorgar derechos políticos.

Asimismo, el constitucionalismo español, pese a su efímero y condicionado paso por la isla, dejó alguna impronta en el tema de la propiedad, al ser la primera vez que se reconoció como derecho y se le otorgaron ciertas garantías. El constitucionalismo liberal cubano, al abordar estos temas, mantuvo una cierta coherencia doctrinal, al admitir los mismos postulados teóricos que el español, pese a las importantes diferencias en su seno en cuanto a contenido y alcance.

\footnotetext{
${ }^{62}$ Pichardo, Hortensia, Documentos para la historia de Cuba, tomo 1, Cuba, Pueblo y Educación, 1984.
} 
Por último, el fin del ciclo revolucionario estuvo marcado en la Constitución de 1901 por un compromiso entre las dos tendencias del liberalismo cubano, al otorgarle a la propiedad un amplio grupo de garantías, pero reconociendo los postulados del sufragio universal.

\section{Bibliografía}

Álvarez, Clara, "El Estado en cuestión: Cuba y la esclavitud en las Cortes de Cádiz", en Antonio Filiú Franco y Clara Álvarez Alonso, La Cuestión cubana en las Cortes de Cádiz, Madrid, Fundación Coloquio Jurídico Europeo, 2011.

Arango y Parreño, Francisco, Obras completas, vol. 2, La Habana, Imagen Contemporánea, 2005. Bravo Correoso, Antonio, Cómo se hizo la Constitución de 1901, La Habana, Imprenta y Papelería Rambla, Bouza y Cía, 1927.

Carbonell Rivero, Néstor, Guáimaro 10 de abril de 1869-10 de abril de 1919. Reseña histórica de la primera Asamblea Constituyente y primera Cámara de Representantes de Cuba, La Habana, Imprenta de Seoane y Fernández, 1919.

CARR, RAYMond, España 1808 a 1939, Barcelona, Ariel, 1969.

DÁnvila, Manuel, El Libro del propietario, Valencia, Imprenta de José Rius Editor, 1862.

Díaz de EsPada y Fernández de Landa, JuAn José, Papeles, La Habana, Editorial Imagen

Contemporánea, 2005.

Eliot Morrison, Samuel y Steele Commanger, Henry, Historia de los Estados Unidos de

Norteamérica, tomo 1, México, Fondo de Cultura Económica, 1951.

FaUlKner, Harold Underwood, Historia económica de los Estados Unidos, tomo 1, La

Habana, Ainsenson, Editorial de Ciencias Sociales, 1972.

Fernández Mellén, Consolación, "En mejor servicio de Dios y del Rey: El obispo Espada y la reforma eclesiástica de la iglesia habanera", en Juan Bosco Amores Carredano, Los tiempos de Espada: Vitoria y La Habana en la era de las revoluciones atlánticas, España, Universidad del País Vasco, 2014.

Fernández Viciedo, Yuri, “Los 'fieles' orígenes del constitucionalismo cubano”, en Carlos Villabella Armengol (comp.), Hitos constitucionales del siglo XIX cubano, México, Instituto de Ciencias Jurídicas, 2011.

Ferrara, Orestes, Las ideas politico sociales en las constituciones cubanas, Madrid,

Talleres Tipográficos Marsinoa, 1945.

HernándeZ Corujo, EnRiQue, Los fundamentos históricos y filosóficos de la Constitución de 1901, La Habana, Editorial Lex, 1953.

Hоскетт, Homer, The Constitutional history of the United States, Nueva York, Macmillan, 1959.

Jefrerson, Thomas, The Political writings of Thomas Jefferson, Nueva York, The Liberal Arts Press, 1959.

Lazcano y Mazón, Andrés, Las Constituciones de Cuba, Madrid, Ediciones Cultura Hispánica, 1952. 
Locke, John, Ensayo sobre el gobierno civil, Buenos Aires, Aguilar, 1960.

Morrilla, José María, Breve tratado de Derecho administrativo español general del

Reino y especial de la isla de Cuba, La Habana, Sin editor, 1847.

Pichardo, Hortensia, Documentos para la historia de Cuba, tomo 1, Cuba, Pueblo y

Educación, 1984.

Ponte Domínguez, Francisco, Historia de la Guerra de los Diez Años. Desde su origen hasta la Asamblea de Guáimaro, La Habana, Imprenta El Siglo XX, 1944.

Rodríguez, Rolando, Cuba: la forja de una nación, La Habana, Editorial de Ciencias Sociales, 2005.

Rodríguez Abrahantes, Dagoberto, Historia de los Estados Unidos. Selección de Lecturas, tomo 1, La Habana, Félix Varela, 2003.

RoldÁn de MonTAud, InÉs, La Restauración en Cuba. El fracaso de un proceso reformista, Madrid, Consejo Superior de Investigaciones Científicas - Centro de Humanidades - Instituto de Historia, 2000.

Santamaría García, Antonio y Vázquez Cienfuegos, Sigfrido, "El Discurso de Arango en su contexto histórico”, en Juan Bosco Amores Carredano, Los tiempos de Espada: Vitoria y La Habana en la era de las revoluciones atlánticas, España, Universidad del País Vasco, 2014.

Sevilla Andrés, Diego, Constituciones y otras leyes y proyectos politicos de España, tomo 1, Madrid, Editora Nacional, 1969.

Torremocha, Manuel, “Constitución francesa 1791”, IEs Las Musas. [Consulta: 33 de enero, 2010]. Disponible en: www.ieslasmusas.org/geohistoria/constiticionfrancesa 1791.pdf

Torres Cuevas, Eduardo y Loyola Vega, Oscar, Historia de Cuba 1492-1898: Formación y liberación de la Nación, La Habana, Editorial Pueblo y Educación, 2002.

Varela Suanza Carpegna, Joaquín, "La construcción del Estado en la España del siglo XIX. Una perspectiva constitucional”, en Carlos Manuel Villabella Armengol, (comp.), Hitos constitucionales del siglo XIX cubano, México, Instituto de Ciencias Jurídicas de Puebla, 2011.

Zamora, Juan Clemente, Nuevas Orientaciones en materia constitucional, La Habana, Editorial Atalaya, 1939. 